\title{
Acceptability of local made baits for oral vaccination of dogs against rabies in the Philippines Roland Estrada*1, Adriaan Vos ${ }^{2}$ and De Leon RC3
}

Address: ${ }^{1 D M M M S U}-$ Institute of Veterinary Medicine, Bacnotan, La Union, Philippines, ${ }^{2}$ IDT GmbH, PSF 214, o6855, Rosslau, Germany and 3DILG-Provincial Veterinary Office, San Fernando City, La Union, Philippines

E-mail: Roland Estrada* - ovd_philippines@pinoyjustice.com; Adriaan Vos - ad.vos@idt-direct.de; De Leon RC - rcdeleon@pentagon.com

*Corresponding author

\begin{abstract}
Background

In the Philippines, traditional mass dog vaccination campaigns have only achieved limited and transient success in dog rabies control, mainly because a large segment of the dog population is not accessible for traditional parenteral vaccination. Oral vaccination of dogs has been suggested as a supplementary method to increase the overall vaccination coverage of the dog populations involved. For this purpose, it is necessary to identify a suitable bait that is readily accepted by local dogs and that can be prepared without high costs.
\end{abstract}

\section{Materials and Methods}

During a field study, dog bait-acceptance of several baits, made from inexpensive local available material, was examined in the Philippines.

\section{Results}

Of three baits tested, chickenneck, intestine, and boiledintestine, the latter, made from boiled sections of the larger intestine of domestic pigs, had the highest acceptance-rate: none of the dogs that were offered a bait refused it, except for two dogs that ran away when approached.

Other derivatives of the boiled-intestine bait were also accepted by almost all dogs. These baits, using the serosa of the smaller intestine as bait matrix were filled with fish, beef or pork scraps. However, preparation-time was longer and the costs of bait material were higher than those for the boiled-intestine bait (0.01 U\$).

\section{Conclusion}

The boiled-intestine bait can be produced at very low costs using locally available material and is extremely well accepted by local dogs, hence, providing a realistic opportunity to incorporate oral vaccination of dogs in the national rabies programme of the Philippines.

\section{Background}

In many countries, mass dog vaccination campaigns have eliminated dog rabies, and consequently dog-transmitted human rabies. However, in other countries, like the Philippines, little progress has been made in dog rabies control. Dogs (Canis familiaris) remain the most important rabies vector species in the Philippines; almost all human rabies cases are a result of bites from rabid dogs [1]. It appears that a large segment of the dog population is not accessible for parenteral vaccination, resulting in a vaccination coverage too low to interrupt the chain of infection. Under these circumstances, oral vaccination of dogs against rabies (OVD) could be a very useful alternative in rabies control by increasing the number of vaccinated animals within the population. Oral vaccination has been very successful in controlling wildlife rabies in large areas of Europe and North-America [2-4]. 
One of the preconditions of OVD is the development of a suitable bait well accepted by the target population. The machine-made vaccine baits, sometimes called artificial or manufactured baits, used for oral vaccination of wildlife have certain disadvantages when used for OVD. First of all, most countries with dog-mediated rabies have only limited financial resources for rabies control. The imported manufactured baits will therefore be too expensive for these countries. Another disadvantage is that the local dog population is most probably not familiar with the baits (taste, odour and texture). All objects offered to the dogs will be investigated (sniffing, licking) prior to consumption. The chances that external or internal factors will lead to an interruption, and consequently an unsuccessful vaccination attempt, will increase with growing unfamiliarity with the bait. Thus, to limit the risks of interruption the acceptance-threshold of the bait should be as low as possible; the bait should immediately be attractive to the dogs. Baits made from cheap local available material could qualify in this respect, while dogs are most often fed on households leftovers and offal, and thus familiar with these items. During a fieldstudy to test the feasibility of OVD in Turkey $96 \%$ of all dogs accepted the local-made köfte-bait (minced meat mixed with bread) without hesitation [5]. However, baits with a high acceptance by dogs in one area can be refused by dogs in another area, due to different food-preferences and - experiences of the dog populations involved [6]. Hence, it was decided to identify the most suitable bait made from cheap local available material in the Philippines. It was shown that the local-made boiled-intestine bait was extremely well accepted by the local dogs.

\section{Materials and Methods}

A previously described/developed koffe-bait was not considered suitable for the Philippines, due to concerns about it being attractive to humans.
As a reference bait, the chickenhead-bait was suggested. This bait was initially also used for oral vaccination of foxes in Europe. But the larger vaccine capsule intended for dogs could not be slid underneath the skin of the chickenhead. It was therefore decided to replace the chickenhead with larger segments of chickenneck.

As an inexpensive alternative, rinsed segments of intestine was used as a completely new bait (costs per bait:0.01 U\$). These intestine baits were prepared from sections (5-8 long) from the large intestine of domestic pigs (Sus domesticus). After boiling for ten minutes, the baits become more "elastic" and would increase the bait handling time.

Finally, the cleaned serosa of the smaller intestine of pigs was used as a matrix for other baits. These baits were filled with local available materials (Table 1), in order to see if these additives would increase bait-acceptability compared to the intestine bait.

An empty vaccine container $(6.5 \times 3.0 \times 0.7 \mathrm{~cm})$, a polyvinyl-chloride capsule with serrated edges and sealed with an aluminum cover foil, was placed manually, inside the baits. All dogs offered a bait were owned, some of the animals were restricted, but most animals were free roaming and were found in doorways, allays, yards, or on the streets adjacent to the owners dwellings.

Young dogs, less than three months old, were excluded from the bait trials. The baits were offered to the dogs by the vaccinators only, baits were not handed out to the owners.

The bait trials with the (boiled and raw) intestine-and chickenneck baits were carried out in rural areas around Agoo and the North La Union campus of Don Mariano Marcos Memorial State University campus in Bacnotan, both in the province of La Union, Philippines.

Table I: Description and costs (only costs of material) of baits with the scrosa of the smaller intestine of pigs as bait matrix (scrosa - bait).

\begin{tabular}{|c|c|c|c|}
\hline Type & Ingredients & Study Area & $\begin{array}{l}\text { Costs per bait } \\
\text { US\$; }\end{array}$ \\
\hline A & $\begin{array}{l}\text { Boiled ground beef and meat scraps (hide, omentum, ligaments etc.) of } \\
\text { domestic cattle (Bos Taurus) and domestic water buffalo (Bubalus } \\
\text { bubalus) }\end{array}$ & Suburban (Agoo) & 0.02 \\
\hline B & $\begin{array}{l}\text { Ground scraps (fat, lung, ligaments, etc) from domestic pigs (Sus domesti- } \\
\text { cus) }\end{array}$ & Urban (Baguio) & 0.02 \\
\hline C & Boiled scraps of slimy mackerel (Scomber australaticus) & Suburban \& Urban (Agoo, Baguio) & 0.03 \\
\hline $\mathrm{D}$ & Boiled scraps of cheerootfish (Decapterus macrosoma) & Urban(Baguio) & 0.05 \\
\hline$E$ & Boiled scraps of skipjack tuna (Katsuwonus pelamis) & Suburban (Agoo) & 0.02 \\
\hline
\end{tabular}


Table 2: The results of the bait-acceptance trials with chicken neck - and (boiled and raw) intestine-bait.

\begin{tabular}{lccccc}
\hline Bait & Total & Accepted & Not-Accepted & Unknown & Not-offered \\
\hline Chickenneck & 27 & 17 & 5 & 1 & 4 \\
Raw Intestine & 32 & 23 & 5 & - & 2 \\
Boiled Intestine & 57 & 53 & & 2 \\
\hline
\end{tabular}

Table 3: Fate of the vaccine container incorporated in the (boiled and raw) intestine - and chickenhead bait ( $P$-punctured and discarded, NP-not punctured and discarded, SW - swallowed, SW/P - punctured and swallowed)

\begin{tabular}{lccccc}
\hline Bait & Total & P & NP & SW & SW/P \\
\hline Chickenneck & 17 & 14 & 2 & 1 & - \\
Raw Intestine & 23 & 16 & 3 & 3 & 1 \\
Boiled Intestine & 53 & 47 & 2 & 3 & 1 \\
\hline
\end{tabular}

A bait was recorded as 'accepted' when the dog had actually consumed the entire bait. When the dog only licked or sniffed at the bait, or did not show any interest at all, it was recorded as 'not accepted'. Sometimes, dogs would take the bait and ran away with it, here the outcome of the vaccination attempt was classified as 'unknown'. Although the dog accepted the bait, it could not be ruled that the animal would cached the bait for later consumption, or would loose interest and abandon it. If a dog ran away, before a bait was offered, it was recorded as 'not offered'. However, sometimes it was possible to offer another bait to the same dog during a second vaccination attempt. Otherwise, the animals were only once offered a bait. Of course, it cannot be avoided that some unrestricted dogs were encountered twice or more often. To avoid this as much as possible, the neighbourhoods were visited only once. During the field trials with the (boiled and raw) intestine- and chickenneck baits, also the fate of the vaccine container was recorded; P-the discarded container was punctured, NP- the discarded container was not punctured; SW-container was swallowed almost immediately, probably not punctured, SW/P-container was punctured and subsequently swallowed. An animal was considered vaccinated when it had accepted the bait and, subsequently, the vaccine container was punctured $(\mathrm{P}$ and SW/P). All vaccine containers were recovered by the vaccinators and the fate determined. The field trials were approved by the appropriate local and national committees and authorities.

\section{Results}

The (boiled and raw) intestine and chickenneck baits were offered to 116 dogs, 11 and 105 restricted and unrestricted owned dogs, respectively. The results are shown in Table 2, the acceptance-rate was very high for all three baits tested. A total of seven dogs could not be offered and did not accept any bait. Five dogs fled when a bait was thrown towards the animals, one of these baits was taken by a chicken before it could be recollected by the vaccinators. During four other attempts, the bait offered was snatched away by another dog; two of these dogs could be offered a new bait.

Five dogs did not accept the intestine baits and four dogs did not accept the chickenneck bait. Another dog initially accepted the chickenneck bait and walked away with it, however the animal dropped the bait after a few meters and disappeared. The fate of the vaccine containers is summarized in Table 3. Thus, the actual 'vaccinationcoverage' of the total number of animals approached minus the dogs that ran off with the bait (unknown) for the three different baits is: chickenneck $-53.5 \%$ (14/26), intestine $-54.8 \%$ (17/31), and boiled intestine -87.3\% (48/ 55 ). The acceptance-rate of the serosa-baits with different local-available additives are listed in Table 4.

\section{Discussion}

Bait acceptance trials are an essential part of examining the feasibility of oral vaccination of dogs against rabies [7]. Several studies provided already valuable data on this subject [8-13]. To determine bait-preference, it is suggested to use a two-choice-food-preference test [10]. 
Table 4: The acceptance - rate (\%) and $95 \%$ confidence interval of the different serosa - bait types.

\begin{tabular}{ccccc}
\hline Type & Number of baits tested & Acceptance rate (\%) & 95\% confidence interval \\
\hline A & 73 & $\mathbf{8 5}$ & $\mathbf{7 6}$ & $\mathbf{9 0}$ \\
B & 20 & $\mathbf{9 8}$ & 78 & 98 \\
C & 28 & 100 & 90 & 100 \\
D & 22 & 100 & 87 & 100 \\
E & 75 & 100 & 96 & 100 \\
\hline
\end{tabular}

However, this test is not very suitable under field conditions when offering baits to unrestricted dogs. Hence, it was decided to offer dogs only one type of bait. Although, the incorporation of a biomarker in the baits is suggested as a precondition for bait studies, no bait marker was used in these trials; it was not considered necessary because baits were offered directly to the animals and the outcome of the vaccination attempt could be directly assessed.

Initially the WHO was in favour of inexpensive baits that were producible under local conditions with (partially) locally available products [14]. Later on it was suggested that baits should be producible in large repeatable batches [15], and the preference was given to manufactured baits [16]. Although several studies indicate high bait-acceptance of manufactured baits $[17,18]$, generally baits made from cheap local-available material had a much higher acceptance rate. Costs associated with this novel approach will ultimately determine the feasibility of OVD. Dog rabies is mainly a problem in developing countries. So, even with a mass-produced manufactured bait accepted at almost the same rate as baits made from locally available material, costs associated with the former will most probably limit its use [19]. Not only the direct costs of imported manufactured baits will place a heavy burden on the often limited funds available for $\mathrm{dog}$ rabies control in developing countries, but also the additional costs associated with the transportation and storage of the relatively heavy manufactured baits, compared to the shipment of only the vaccine-loaded containers. Even if a production facility of these baits is established locally, the price will still exceed that of baits made from local-available material, like the boiled-intestine or köfte bait. To include local labour costs required for the preparation of the local-made baits like the intestine-bait in a cost-benefit analysis is not justified. Simply, because in most countries with dog-mediated rabies, there is no shortage of qualified personnel or available time, it is the lack of financial resources and material that causes problems. However, the cost estimate for labor is very minimal as it requires only a single individual to boil and make hundreds of segmented intestine baits. The final product is then stored on ice in styro-foam boxes without further refrigeration.

Thus, the very low costs of the boiled intestine-bait (o.01 U\$) is an important advantage over (imported) manufactured baits. Also, this bait is extremely well accepted by the local dogs in the Philippines; all animals accepted the bait except for two dogs that ran away. The use of bait additives, like beef, fish and pork scraps (serosa-baits) will only increase the price of the baits. Also, the preparation time of the baits will increase considerably (i.e. deboning of fish, grinding, etc.). The other two baits, chickenneck - and raw-intestine bait, were not accepted as well as the boiled-intestine bait. Furthermore, it was observed that dog owners in the Philippines were reluctant to have raw bait material from chickens offered to their dogs. They assumed that the dogs would develop a taste for free-roaming poultry. Boiling the intestine increased its effectiveness; the material became more difficult to chew, so bait handling-time increased, and also the increased elasticity prevented the vaccine container from becoming separated from the matrix (intestine section). Furthermore, pig intestine is a popular viand in the country and once boiled, pose no threat for potential pathogens.

It does not automatically mean a successful vaccination attempt when a dog accepts a bait. Not only is the vaccine container sometimes swallowed before it is punctured, so no vaccine virus is released into the oral cavity, also dogs can separate the vaccine container from the bait material, or the intact vaccine container drops out of the dog's mouth because it has poor adherence with the bait matrix. Even when the container is punctured, it does not guarantee that the animal is vaccinated; the vaccine container is sometimes poorly punctured and varying amounts of vaccine is retained within the containers. Finally, vaccine virus maybe spilled from the container and lost into the ground. 
Notwithstanding, the assessed 'vaccination-coverage' (87.3\%) of the boiled intestine-bait was extremely high, especially considering that most dogs approached were unrestricted. For example, during a field-study in Mexico, only $83(50.9 \%)$ of 163 free-roaming dogs that were approached accepted the manufactured baits, meanwhile $89 \%$ of household dogs accepted and consumed the same type of baits completely. The difference in bait acceptance was mainly a result of the fact that already $23 \%$ of the free-roaming dogs fled before a bait was offered. Hence, overall bait acceptance is not only determined by the palatability of the baits, but also a result of experience how to approach and offer a bait to the dogs [20]. This aspect is often overlooked or ignored, but especially the approach of unrestricted dogs needs practice in order to maximize overall bait acceptance.

\section{Conclusions}

Baits made from locally available material, like the boiled intestine bait, have a high acceptability by the local dogs and together with their relatively low costs offer new opportunities to overcome the present impasse in dog rabies control in the Philippines.

However, it is necessary to examine the efficacy of the vaccine-bait combination for every locally-made bait used. Fortunately, the efficacy of the boiled intestine bait, in which a vaccine container filled with the livemodified oral rabies virus vaccine SAD B19 (Street Alabama Dufferin) was placed, was already proven in indigenous Turkish dogs during a relevant challenge experiment [19].

\section{Competing interests}

none declared

\section{Acknowledgement}

We are most grateful to the students, Soshiel Sibolboro, Mikael Crisologo and Philip Montano of the Institute of Veterinary Medicine at DMMMSU, Bacnotan, La Union for helping prepare the baits.

\section{References}

I. Miranda MEG: Rabies in humans in the Philippines In: Fourth International Symposium on Rabies Control in Asia, 5-9 March Hanoi, Vietnam. Abstract Book 200167

2. Stöhr K, Meslin F-X: Progress and setbacks in the oral immunization of foxes against rabies in Europe. Veterinary Rec 1996, 139:32-35

3. Müller T, Schlüter $\mathrm{H}$ : Oral immunization of red foxes (Vulpes vulpes L) in Europe: A review. J Etlik Veterinary Microbiology 1998, 9:35-59

4. Macinnes D, Smith SM, Tinline RR, Ayers NR, Bachmann P, Ball DGA, Calder LA, Crosgrey SJ, Fielding C, Hauschildt P, et al: Elimination of rabies from red foxes in eastern Ontario. J Wildlife Discovery 2001, 37:119-132

5. Schuster P, Gülsen N, Neubert A, Vos A: Field trials evaluating bait uptake by an urban dog population in Turkey. J Etlik Vet. Microbiology 1998, 9:73-8I

6. Perry BD, Brooks R, Foggin M, Bleakley J, Johnston DH, Hill FWG: A baiting system suitable for the delivery of oral rabies vaccine to dog populations in Zimbabwe. Vet. Rec 1988, I 23:76-79
7. Matter H: Oral immunization of dogs: analysis of dog populations and bait delivery systems. In: Rabies Control in Asia (Edited by. Dodet B, Meslin FX) Paris, Elsevier 199747-59

8. Frontini MG, Fishbein DB, Ramos JG, Collins EF, Torres JMB, Huerta GQ, Rodriguez JG, Belotto AJ, Dobbins JG, Linhart SB, et al: A field evaluation in Mexico of four baits for oral rabies vaccination of dogs. Am J Trop Med Hyg 1992, 47:310-316

9. Kharmachi $\mathrm{H}$, Haddad N, Matter $\mathrm{H}$ : Tests of four baits for oral vaccination of dogs against rabies in Tunisia. Vet $\operatorname{Rec} 1992$, 1 30:494

10. Linhart $S B$ : Bait formulation and distribution for oral rabies vaccination of domestic dogs: an overview. Onderstepoort J Vet Res 1993, 60:479-490

II. Matter H, Kharmachi H, Haddad N, Ben Youssef S, Sghaier, Ben Khelifa R, Jemli J, Mrabet L, Meslin FX, Wandeler Al: Test of three bait types for oral immunization of dogs against rabies in Tunisia. Am J Trop Med Hyg 1995, 52:489-495

12. Linhart SB, Baer GM, Balderas Torres JM, Engeham RM, Flores Collins E, Meslin FX, Schumacher L, Taweel A-H El, Wlodkowski JC: Acceptance of candidate baits by domestic dogs for delivery of oral rabies vaccines. Ondersteport J Vet Res 1997, 64: I I5-124

13. Müller W, Güzel T, Aylan O, Kaya, Cox J, Schneider L: The feasibility of oral vaccination of dogs in Turkey - an European Union supported project. J Etlik Vet. Microbiology 1998, 9:6I-7I

14. World Health Organization: Report of WHO Consultation on oral immunization of dogs against rabies, Geneva, 26-27 February 1988. Geneva 1988

15. World Health Organization: Second WHO consultation on oral immunization of dogs against rabies. Geneva |991

16. World Health Organization: Report of the fifth consultation on oral immunization of dogs against rabies, Geneva, 20-22 June 1994. Geneva 1994

17. Bishop G: Increasing dog vaccination coverage in South Africa: Is oral vaccination the answer? In: Fourth International Symposium on Rabies Control in Asia, 5-9 March 2 I, Hanoi, Vietnam. Abstract Book 200II2I

18. Harischandra PAI PAI: Increasing dog vaccination coverage in Sri Lanka: Is oral vaccination the answer? In: Fourth International Symposium on Rabies Control in Asia, 5-9 March Hanoi, Vietnam. Abstract Book 200III7

19. Aylan O, Vos A: Efficacy of oral rabies vaccine baits in indigenous Turkish dogs Inf $\operatorname{Dis} \operatorname{Rev} 2000$, 2:74-77

20. Güzel N, Leloglu N, Vos A: Evaluation of a vaccination campaign of dogs against rabies, including oral vaccination, in Kusadasi, Turkey. J Etlik Vet Microbiology 1998, 9:121-134

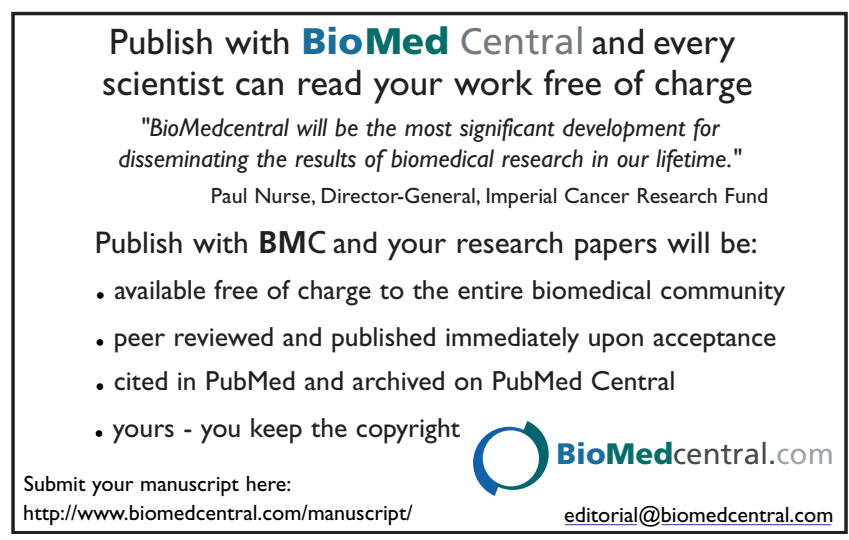

